\title{
Proposta de uma Ferramenta de Reforço de Vocabulário na Educação de Surdos
}

\author{
Bruno Pereira Brito - UFPA - Universidade Federal do Pará \\ britodi@gmail.com \\ Benedito de Jesus Ferreira - UFPA - Universidade Federal do Pará \\ ferreira@ufpa.br
}

\begin{abstract}
Resumo. O surdo apresenta dificuldade na compreensão da língua portuguesa, devido a limitação de comunicação e a estratégias educacionais inadequadas a sua realidade. A proposta da ferramenta é direcionada para o aprendizado do vocabulário de alunos surdos, baseada em pesquisas da literatura e observações de necessidades em uma escola especializada na educação de surdos. A ferramenta visa auxiliar o processo de aprendizado de vocábulos da língua portuguesa, através da utilização da Língua Brasileira de Sinais, escrita do português e cenários ilustrados. Em uma primeira aplicação a ferramenta impactou de forma favorável na aquisição de novos vocabulários, deste modo, proporciona melhorias no aprendizado da língua portuguesa e na comunicação dos alunos.
\end{abstract}

Palavra-chave: Língua portuguesa e o surdo, aprendizado de vocabulário e educação especial.

\section{Proposal of a Vocabulary Reinforcement Tool in Deaf Education}

Abstract. Deaf has difficulty in understanding the Portuguese language, due to limitation of communication and inadequate educational strategies your reality. The proposed tool is intended for learning the vocabulary of deaf students, based on literature research and needs of observations in a school specializing in deaf education. The tool aims to help the Portuguese language vocabulary learning process through the use of Brazilian Sign Language, writing Portuguese and illustrated scenarios. In a first application the tool impacted favorably on acquiring new vocabularies thus provides improvements in learning the Portuguese language and communication students.

Keywords: Portuguese Language and the deaf, vocabulary and special education learning.

\section{Introdução}

Investigar a realidade educacional do aluno surdo, no que se refere a interpretação de texto em língua portuguesa e a compreensão do significado do vocabulário, destaca a comunicação verbal como fator significativo no processo instrutivo.

Sobre este aspecto, Carvalho e Ferreira (2011), Hautrive e Souza (2010) e Santos e Favero (2014), concordam que o problema na compreensão da língua portuguesa do aluno surdo, é acentuado pela confusão no significado do vocabulário e pela dificuldade de socialização.

O aluno ouvinte quando inicia o processo de alfabetização, possui um conhecimento prévio da língua portuguesa, pois convive com familiares ouvintes. Neste contexto, o indivíduo surdo desconhece o português, por não ter contato com a língua.

As escolas especializadas na educação de alunos surdos, adotam o bilinguismo posicionando a Língua Brasileira de Sinais (Libras) como língua materna e fundamental para o aprendizado da segunda língua, o português. 
Neste cenário, Quadros (2005), Pereira (2009) e Camatti e Lunardi-Lazzarin (2010) concordam que a inserção desses alunos em escolas bilíngues especializadas na educação de surdos, utilizem a Língua Brasileira de Sinais na comunicação e no acesso ao conteúdo das disciplinas ministradas.

Diversos fatores influenciam no aprendizado do aluno surdo, sendo a Libras um elemento fundamental para o aprendizado. A Língua Brasileira de Sinais é a língua de instrução e de comunicação desses alunos.

A utilização de recursos visuais na educação de surdos é extremamente relevante para o aprendizado, ajudando na interpretação e dedução do significado.

Neste sentido, a utilização de recursos tecnológicos associados a elementos visuais promove o entendimento do significado. Para Figueiredo e Guarinello (2013) a valorização de práticas que estimulem os aspectos visuais, auxiliam na interação do sujeito surdo e possibilita sua inserção em práticas letradas.

As escolas especializadas na educação de alunos surdo debatem sobre o atendimento individualizado, contando com psicólogos, pedagogos, fonoaudiólogos e professores, visando realizar um atendimento diferenciado.

Neste cenário, após o diálogo com integrantes de uma escola especializada e pesquisas na literatura, determinamos algumas metodologias de ensino-aprendizado da língua portuguesa fundamentada em uma abordagem bilíngue.

Muitas metodologias descrevem o processo de aprendizado do aluno surdo, em especial a compreensão do significado de vocabulários e a interpretação de texto na língua portuguesa.

A partir desta análise de métodos e estratégias que facilitam a dedução do significado das palavras, foi desenvolvido uma ferramenta computacional que contemple os recursos estudados.

Neste contexto, é pertinente a construção de uma ferramenta que agrupe as principais características que favorece o aprendizado do aluno surdo, auxiliando no processo de interpretação e reconhecimento da escrita em língua portuguesa, visando a aquisição e reforço do aprendizado e compreensão do significado do vocabulário.

\section{Aspectos contemplados no desenvolvimento da proposta}

Considerando a proposta bilíngue do instituto pesquisado e as entrevistas realizadas com docentes e coordenadores, definimos as principais necessidades de apoio dirigidas ao aprendizado da língua portuguesa do aluno surdo a partir da compreensão do significados de adjetivos.

Dentre as características estudadas, contemplamos na ferramenta metodologias que deslumbre as especificidades do surdo, como a exploração de recursos visuais, a Libras como língua de instrução e de apoio para a compreensão do língua portuguesa.

Outras recursos como a possibilidade de acompanhamento individualizado, visto que as atividades de reforço podem ser direcionados pelo professor de acordo com a necessidade do aluno.

\subsection{Potenciais das TICS na educação de surdos}

Os recursos tecnológicos tem a possibilidade de expandir o conhecimento e ampliar seu acesso. Neste aspecto, Soares (2013) salienta que o indivíduo surdo, que recebe estimulo de ambientes favorável de aprendizado, tem a possibilidade de ampliar sua criatividade e formar sua personalidade. 
A simples absorção dos recursos tecnológicos na educação do aluno surdo, não estabelece um ganho educacional. Nessa direção, devemos apenas considera-lo como um fator que colabora com possíveis transformações na educação, e não uma solução para a problemática do aprendizado do aluno surdo.

$\mathrm{Na}$ educação de surdos, os recursos tecnológicos aliados a estratégias educativas adequadas fomentam o aprender de forma interativa, uma vez que é necessário reconhecer as potencialidades da tecnologia e tomar consciência da realidade em que a escola está inserida, evitando assim, a mera informatização do ensino. (SANTOS, FAVERO, 2014, p.2)

\subsection{Desmembramento da pesquisa}

A pesquisa foi dividida em fases sequencias correspondente a Observação, Aplicação e Análise, sendo a fase Aplicação segmentada em três etapas representadas pela Coleta Inicial, Ensino-Fixação e Coleta Final (ver Figura 1).

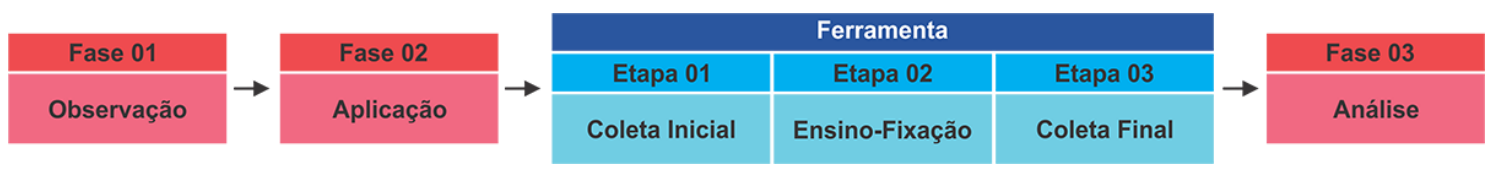

Figura 1 - Representação das fases da pesquisa e etapas da ferramenta

A fase de Observação, é a primeira, que contempla o levantamento científico e as informações referentes ao contato com alunos, docentes e coordenadores em uma escola especializada na educação de surdos. Nesta fase foram levantados dados literários e foram observados o comportamento do aluno e as metodologias de ensino empregadas em sala de aula.

A segunda fase, relativa a Aplicação, é a responsável pelo desenvolvimento da ferramenta, sendo desmembrada nas etapas de Coleta Inicial, Ensino-Fixação e Coleta Final. Com a conclusão desta fase foi possível realizar teste na usabilidade da ferramenta, apurando sua funcionalidades e o comportamento do aluno. Esta fase é responsável pela coleta de dados no emprego da ferramenta.

A fase de Análise corresponde a finalização da pesquisa, sendo comparados os dados coletados na fase de Aplicação. Nesta fase, foi investigado as principais evidencias da pesquisa relacionadas a compreensão do significado e interpretação de texto em língua portuguesa.

\subsection{Caracterização e descrição da ferramenta}

$\mathrm{Na}$ escola especializada em educação de surdo em estudo, os alunos ingressam no primeiro ano e permanecem até o quarto ano do ensino fundamental em turno integral.

$\mathrm{O}$ aluno surdo em escolas especializadas, possui o acompanhamento de professores, psicólogos e fonoaudiólogos, participando de atividades realizadas não apenas em sala de aula, laboratório de informática e atividades esportivas na instituição.

A partir do quinto ano o aluno é integrado ao ensino regular, frequentando a mesma escola que o aluno ouvinte. Neste estágio a escola especializada continua realizando o acompanhamento escolar no formato de reforço.

Na pesquisa, selecionou-se 8 alunos que já estavam integrado na escolas regulares e recebiam atendimento no turno contrário da escola especializada.

A seleção dos alunos participantes foi acompanhada por professores e psicólogos da instituição, visando selecionar alunos do quinto e sexto ano. Cada série selecionada foi composta por 4 alunos que possuem maior dificuldade na língua portuguesa. 
Os alunos participantes utilizaram uma ferramenta computacional que o auxiliará no aprendizado de vocabulários da língua portuguesa, visando aprimorar o entendimento dos vocábulos estudados.

$\mathrm{Na}$ utilização da ferramenta os alunos deveram executar determinadas etapas que medirá sua capacidade de interpretar o significado das palavras, o reconhecimento da escrita do português, associado com ilustrações e Libras.

A primeira fase da pesquisa será direcionada para o aprendizado de adjetivos, apresentando os vocábulos em pares no formato de comparação. Nesta etapa será explorada a relação do adjetivo com seu respectivo oposto, como no exemplo de associação do adjetivo grande ao adjetivo pequeno.

Para validar a ferramenta, desmembramos sua aplicação em três etapas distintas e sequenciais. Na primeira etapa denominada de Coleta Inicial, foi desenvolvido uma atividade no formato de jogo de encaixe que relaciona o adjetivo com seu respectivo oposto, através apenas da associação da escrita em língua portuguesa (ver Figura 2).

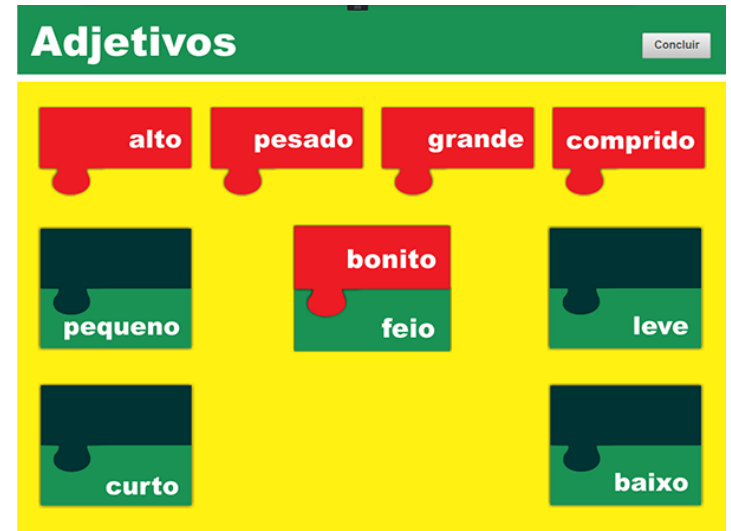

Figura 2 - Coleta Inicial: Atividade - português escrito x português escrito

A etapa de Coleta tem o objetivo de recolher informações do aluno, relacionadas ao entendimento do significado do vocabulário apresentado. Nesta etapa, levantamos a hipótese do aluno reconhecer a escrita e o significado do adjetivo em estudo. Esse procedimento, será importante para compararmos o conhecimento existente do aluno com o adquirido depois de utilizar a ferramenta.

A segunda etapa denominada de Ensino-Fixação, exibira cenários ilustrados que apresentará o significado de oito adjetivos associados aos pares em cada ciclo. Nesta etapa, o aluno construirá o conhecimento selecionando a ordem que os cenários serão estudados (ver Figura 3).

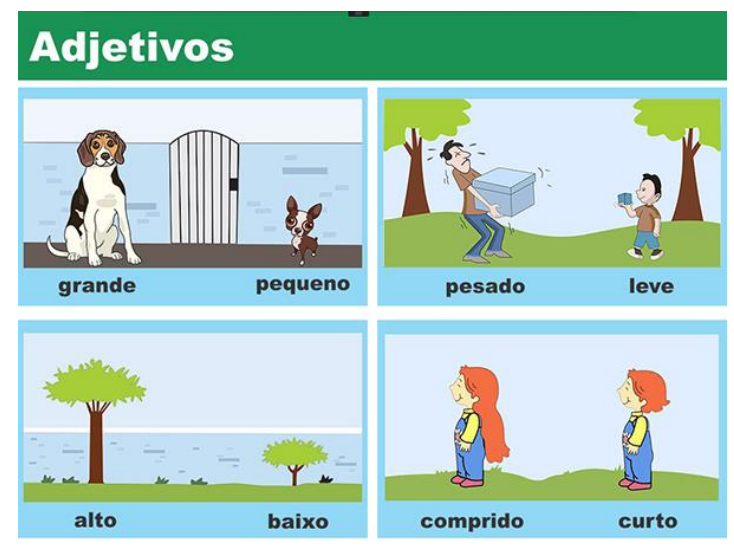

Figura 3 - Ensino-Fixação: Seleção de cenários. 
Após a seleção do cenário será iniciado o processo de aprendizado da ferramenta, que apresentará uma associação de elementos de auxílio a compreensão do significado do adjetivo.

Nesta etapa apresentaremos a escrita do adjetivo em língua portuguesa e seu respectivo alfabeto manual (soletrar em Libras), criando uma associado do cenário ilustrado com o vocábulos em estudo (ver Figura 4).

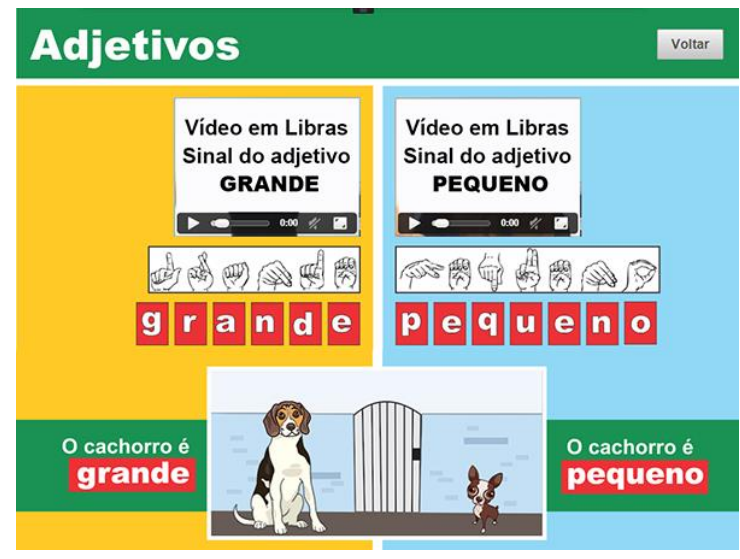

Figura 4 -Ensino-Fixação: Visão de ensino do primeiro cenário

Ainda na visão de Ensino-Fixação e após a seleção do cenário, foi apresentado uma frase escrita em língua portuguesa que exemplifica o vocabulário em estudo. Para cada adjetivo foi mostrado um vídeo em Libras que exibiu seu respectivo sinal.

Após o percurso dos quatro cenários do ciclo de aprendizado, o aluno será direcionado a área de fixação da ferramenta, sendo apresentado uma atividade que associara os adjetivos em pares, com o objetivo de integrar a ilustração com sua correta escrita em língua portuguesa (ver Figura 5).

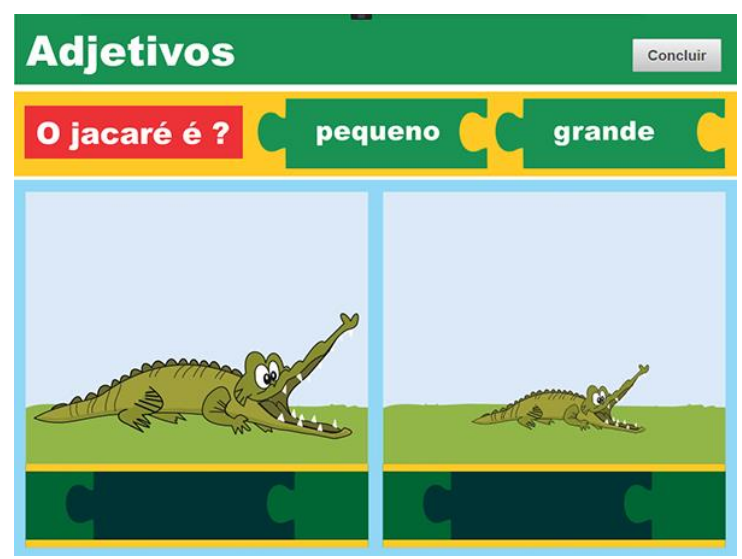

Figura 5 - Ensino-Fixação: Atividade - português escrito x ilustração

A atividade representada na Figura 5, visa criar um ambiente favorável de interpretação do significado do adjetivo, através da associação da ilustração e a escrita do português. Neste ponto, o aluno receberá um feedback (Acertou|Errou), sendo possível realizar a atividade mais uma vez caso tenha errado de primeira.

$\mathrm{Na}$ terceira e última etapa da ferramenta, denominada de Coleta Final, recriamos a primeira atividade com uma reorganização das palavras, visando que o aluno refaça a atividade após completar a etapa anterior de Ensino-Fixação.

O propósito da Coleta Final é confrontar as informações colhidas nessa etapa, com os dados armazenados na Coleta Inicial. Neste contexto, foi realizado um comparativo 
entre a quantidade de acertos do aluno, antes e depois de ser submetido a etapa de EnsinoFixação (ver Figura 6).

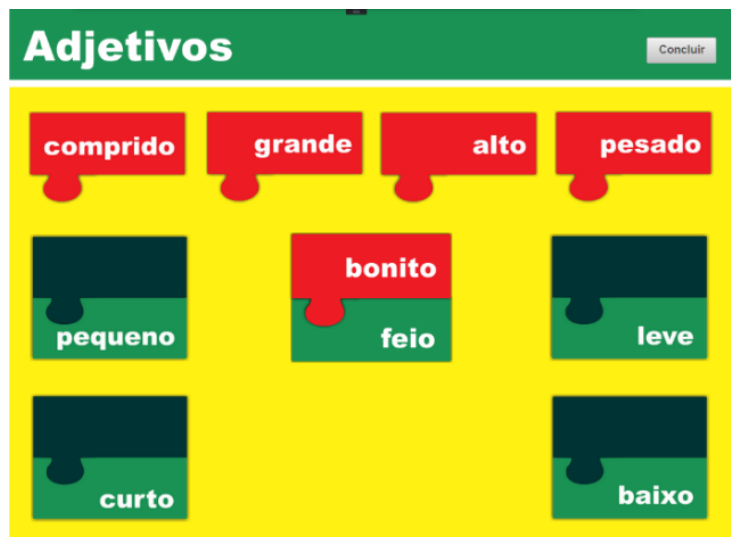

Figura 6 - Coleta Final: Atividade - português escrito x português escrito

Com a apresentação das etapas de Coleta Inicial, Ensino-Fixação e Coleta Final, fechamos o primeiro ciclo da ferramenta.

\section{Resultados esperados}

Em um primeiro momento foi explicado as funcionalidades da ferramenta para o aluno, detalhando as etapas que deveriam ser cumpridas, para a realização da atividade proposta.

No estudo, cada aluno realizou as atividades individualmente, auxiliados por duas professoras da escola, que junto ao pesquisador acompanharam o desenvolvimento do aluno. Cada passo do aluno na utilização da ferramenta foi registrado no banco de dados.

Para a implantação inicial da fase de Aplicação, definiu-se previamente que seriam coletado dados correspondentes a três ciclos, que corresponde a 24 adjetivos por aluno.

Os dados coletados foram submetidos ao teste estatístico T Student pareado, que comparou os dados colhidos antes e depois do aluno realizar a etapa de Ensino-Fixação.

Essa análise questionará se aluno evoluiu no reconhecimento da escrita do vocábulo e na compreensão do significado do adjetivo em estudo.

Em uma análise inicial dos dados coletatos, verificou-se que houve um crescimento na compreensão do significado do vocabulário quando comparados os dados da Coleta Inicial com a Coleta Final (ver Gráfico 1).

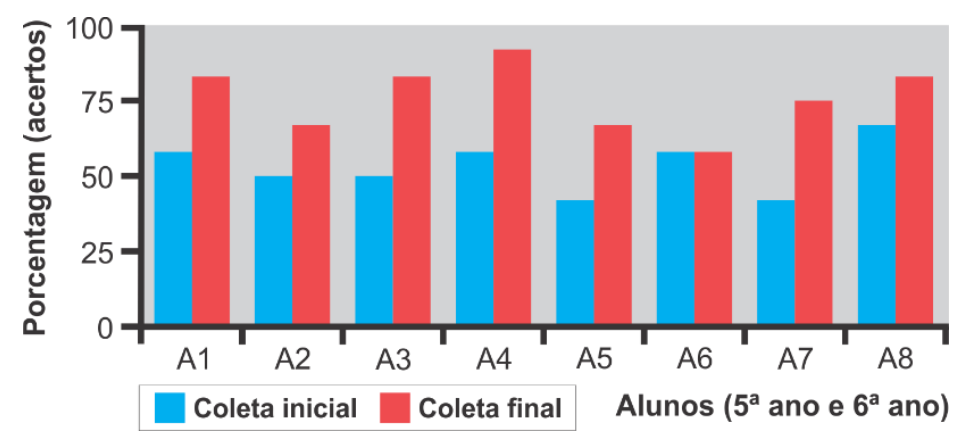

Gráfico 1 - Comparação entre coletas individualizada por aluno 
Ainda nesta perspectiva, foram comparados os dados da Coleta Inicial e Coleta Final, utilizando o teste estatístico T Student pareado.

Admitindo a hipótese nula, um nível de significância igual a 0,05 (5\% de erro) e utilizando os dados (ver Tabela 1), foi encontrado um valor de prova $\mathrm{P}$ de 0,00083 , negando a hipótese nula. Neste cenário, houve um aumento no rendimento dos aluno na Coleta Final.

Tabela 1 - Médias entre as coletas individualizadas por aluno (notas entre 0 e 10)

\begin{tabular}{ccc}
\hline Alunos & Coleta Inicial & Coleta Final \\
\hline 01 & 5,8 & 8,3 \\
02 & 5 & 6,7 \\
03 & 5 & 8,3 \\
04 & 5,8 & 9,2 \\
05 & 4,2 & 6,7 \\
06 & 5,8 & 5,8 \\
07 & 4,2 & 7,5 \\
08 & 6,7 & 8,3 \\
\hline
\end{tabular}

Em uma análise de média e desvio padrão, verificou-se que houve um aumento em relação as duas coletas da ferramenta (ver Gráfico 2).

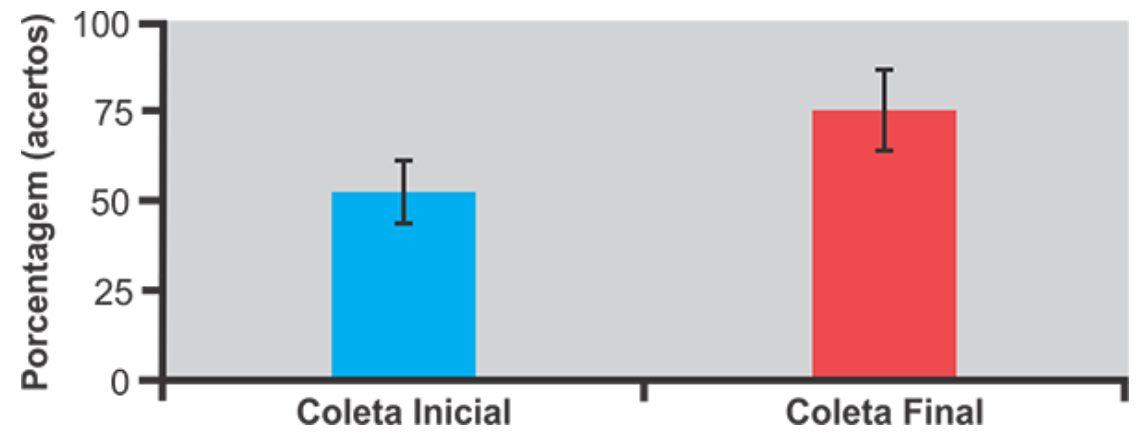

Gráfico 2 - Comparação entre média das coletas e seu respectivo desvio padrão

\section{Considerações Finais}

A pesquisa serviu para identificar as necessidades de alunos e professores no que se refere a dificuldades no aprendizado e ensino na educação de surdos. Neste contexto, outros trabalhos podem complementar a pesquisa, com a inclusão de classes gramaticais como substantivos e verbos.

Ainda nessa perspectiva, avaliamos o desenvolvimento e aplicação da ferramenta como positiva, ajudando na compressão do significado de vocabulários e no reconhecimento da escrita da língua portuguesa.

$\mathrm{Na}$ educação de surdos deve-se priorizar práticas que inclua a especificidade do aluno, utilizando recursos tecnológicos e estratégias educacional que desperte o interesse no aprendizado.

Na prática educacional de alunos surdos, deve-se inserir elementos que facilitem a dedução do significado. Neste ponto, a inserção de ilustrações e vídeos em Libras contribui para a interpretação da língua portuguesa, e colabora com o aprendizado de vocabulário, gerando possíveis desenvolvimento da leitura e interpretação de texto em língua portuguesa. 


\section{Referências Bibliográficas}

CAMATTI, Liane; LUNARDI-LAZZARIN, Márcia Lise. Cultura e comunidade surda: intersecções e emergência do sujeito pedagógico surdo no espaço escolar. Revista de Educação Especial, Santa Maria, v.23, nº39, p.91-102, jan/abr. 2010.

CARVALHO, Nathália Amaral; FERREIRA, Benedito de Jesus. Projeto e implementação de uma ferramenta voltada ao desenvolvimento do vocabulário em língua portuguesa de crianças surdas, Revista Renote, CINTED-UFRGS, v.9, n.3 2011.

FARIAS, Severina Batista. As tecnologias da informação e comunicação e a construção do conhecimento pelo aluno surdo. Universidade Federal da Paraíba, 2006. Dissertação de Mestrado.

FIGUEIREDO, Luciana Cabral; GUARINELLO, Ana Cristina. Literatura infantil e a multimodalidade no contexto de surdez: Uma proposta de atuação. Revista de Educação Especial, Santa Maria, v.26, nº45, p.175-193, jan/abr. 2013.

HAUTRIVE, Giovana Medianeira Fracari; SOUZA, Edna Márcia de. A escrita da língua de sinais como meio natural para a alfabetização de crianças surdas. Revista de Educação Especial, Santa Maria, v.23, nº37, p.181-194, maio/ago. 2010.

QUADROS, Ronice Muller de. O bi do bilinguismo na educação de surdos In: Surdez e bilinguismo. $1^{\text {a }}$ ed. Porto Alegre. 2005: Editora Mediação, v.1, p. 26-36.

PEREIRA, Maria. Cristina da Cunha. Leitura, escrita e surdez / Secretaria da educação. 2.ed. São Paulo. 2009: FDE, 104 p.

SANTOS, Maria Andréia Rodrigues; FAVERO, Eloi Luiz. MCHQ-Alfa: Uma Proposta de Ferramenta para Aprendizagem da Língua Portuguesa na Educação de Surdos Utilizando o Potencial das Histórias em Quadrinhos Mediada por Mapa Conceitual. Revista Renote, CINTED-UFRGS, v.12, nº 1, julho, 2014.

SOARES, Regina Célia Azevedo. Avaliação do vocabulário de crianças surdas inseridas no contexto educacional da pré-escola do instituto nacional de educação de surdos. Universidade Veiga de Almeida, 2013. Dissertação de Mestrado.

VALENTINI, Carla Beatris, BISOL, Cláudia Alquati, CASA, Marcos Eduardo, SGORLA, Esequiel. Um software de autoria para a educação de surdos: integração da língua de sinais e da escrita. Revista Renote, CINTED-UFRGS, v.4, n.2, dezembro/2006. 